\title{
Echocardiographic right heart study in patients with chronic obstructive pulmonary disease
}

\author{
Anish Hirachan ${ }^{1}$, Arun Maskey ${ }^{2}$, Ram Kishore Shah ${ }^{1}$, Bishal K.C. ${ }^{1}$, Miqdaadh Shareef ${ }^{1}$, Madhu Roka ${ }^{2}$, \\ Reeju Manandhar ${ }^{2}$, Kunjang Sherpa ${ }^{2}$, Rabindra Pandey', Dharmanath Yadav², Man Bahadur K.C ${ }^{2}$, Deewakar \\ Sharma ${ }^{2}$.
}

1 Department of Cardiology, National Academy of Medical Sciences, Kathmandu

2 Department of Cardiology, Shahid Gangalal National Heart Centre, Kathmandu

Corresponding author: AnishHirachan,

National Academy of Medical Sciences, Kathmandu, Nepal

Email id : hirachananish@gmail.com

Abstract

Background and Aims: : Chronic obstructive pulmonary disease (COPD) is highly prevalent in the Nepalese population. It is associated with significant extrapulmonary effects among which cardiovascular complications are most common. Echocardiography evaluation mainly focused on effects on the right heart function is a salient tool to evaluate the presence of degree of pulmonary hypertension and also identify those group of patients who need more early aggressive therapy for the underling lung disease. We aimed to prospectively study the patients with diagnosed COPD with echocardiogram for evaluating the right heart .

Methods: An observational, cross sectional study was done on 50 patients with COPD who were admitted at Bir Hospital and underwent echocardiographic evaluation from Dec 2015 -Dec 2016 . All echocardiogaphic parameters focused on right heart and its function were assessed .

Results: Out of total 50 COPD patients studied, majority of them were female (32 patients ,64\%). The mean age group of the studied patients was $60.9 \pm 11.4$ years. Pulmonary hypertension defined as $\mathrm{SPAP}>30 \mathrm{mmHg}$ was evident in all of the patients ; with 30 patients $(60 \%), 14(28 \%)$ and 6(12\%) patients having severe, moderate and mild pulmonary hypertension respectively . RV dysfunction was evident with reduced average TAPSE values $(1.59 \pm 0.38 \mathrm{~cm})$ and elevated RIMP values $(0.58 \pm 0.16)$.

Conclusion: Majority of COPD patients had evidence of pulmonary hypertension. Echocardiogram can be a helpful tool to assess early changes on the right heart size and function in patients with COPD and also monitor these patients for rapid progression of the illness .

Key words: COPD, pulmonary hypertension, RV dysfunction

DOI: http://dx.doi.org/10.3126/njh.v14i2.18496

COPD is currently the 4th leading cause of death in the world and a burning problem among the Nepalese population. Globally, COPD has emerged as the major cause of morbidity and mortality and is expected to become the $3 \mathrm{rd}$ most leading cause of death. ${ }^{1}$ Cardiac manifestations are the most common extra pulmonary effects in COPD patients. ${ }^{2}$ COPD affects pulmonary blood vessels, right ventricle, as well as left ventricle leading to development of pulmonary hypertension, corpulmonale, right ventricular dysfunction, and left ventricular dysfunction. ${ }^{3}$

Right ventricle (RV) dysfunction is common in patients with COPD particularly in those with low oxygen saturation. Pulmonary hypertension (PH) affects the right ventricle function leading to corpulmonale and once developed these patients have poor prognosis. So, the early recognition of $\mathrm{RV}$ dysfunction and pulmonary hypertension may help in treatment and prolonging the survival of the patients with corpulmonale. Echocardiography provides a rapid, noninvasive method to evaluate the right ventricle chamber size and function. ${ }^{4}$ This study was done to identify the prevalence and degree of pulmonary hypertension by echocardiography in COPD patients.

\section{Methods:}

The study was an observational cross sectional, single centre study done at Bir Hospital on 50 consecutive COPD patients admitted at the same centre and undergoing echocardiographic examination from Dec 2015-May 2015. The study was conducted after the approval from the hospital ethical review board. The inclusion and exclusion criteria were as follows:

\section{Inclusion criteria:}

1. All COPD patients attending the echocardiography laboratory of Bir Hospital during the study period.

\section{Exclusion criteria:}

1. Patients who cannot lie for long enough to complete the study 2. H/O of diagnosed chronic lung disease other than COPD like - Interstitial lung disease, Old pulmonary TB with sequalae .

@Nepalese Heart Journal. Nepalese Heart Journal retains copyright and work is simultaneously licensed under Creative Commons Attribution License CC - BY 4.0 that allows others to share the work with an acknowledgement of the work's authorship and initial publication in this journal. 
3. Any systemic disease that can cause pulmonary hypertension,

4. Patients with congenital heart disease, rheumatic heart disease or valvular heart disease

All necessary parameters for RV function by echocardiography were calculated and analysed. Parameters measured include RV and right atrial (RA) size, measure of RV systolic function, as assessed by at least one or a combination of the following: DTI-derived tricuspid lateral annular systolic velocity wave (S'), tricuspid annular plane systolic excursion (TAPSE), and RV index of myocardial performance (RIMP). RV systolic pressure was calculated using the tricuspid regurgitation jet and an estimation of RA pressure based on inferior vena cava (IVC) size and collapsibility. Hence, pulmonary artery systolic pressure (PASP ) was calculated by using continuous wave Doppler and applying the equation below:

$\mathrm{PASP}=4^{*}(\text { peak TR velocity })^{2}+\mathrm{RAP}$

IVC diameter $<2.1 \mathrm{~cm}$ that collapses $>50 \%$ with a sniff suggests normal RA pressure of $3 \mathrm{~mm} \mathrm{Hg}$ (range, $0-5 \mathrm{~mm} \mathrm{Hg}$ ), whereas IVC diameter $>2.1 \mathrm{~cm}$ that collapses $<50 \%$ with a sniff suggests high RA pressure of $15 \mathrm{~mm} \mathrm{Hg}$ (range, 10-20 mm Hg). In scenarios in which IVC diameter and collapse do not fit this paradigm, an intermediate value of $8 \mathrm{~mm} \mathrm{Hg}$ (range, 5-10 mm $\mathrm{Hg}$ ) was used. ${ }^{5}$ TAPSE measures predominatly the longitudinal systolic function and values $<17 \mathrm{~mm}$ is highly suggestive of RV systolic dysfunction. Right atrium pressure can be estimated with the IVC diameter and its changes with respiration.

The calculations were done by Microsoft Excel 2007, and Statistical Package for Social Sciences, SPSS version 20; and the data were presented in the form of tables and diagrams. Appropriate statistical tests were carried out to compare the data, and a level of significance of 0.05 was used. Values were expressed as mean \pm standard deviation.

\section{Results:}

Majority of the patients were female $64 \%(\mathrm{n}=32)$ with the mean age of $60.9 \pm 11.4$ years. Forty seven patients $(90 \%)$ studied had significant ECG abnormality out of which $\mathrm{P}$ 'pulmonale was the most common (45 patients , $90 \%$ ) while atrial arrhythmias in the form of Atrial fibrillation (AF) or Multifocal tachycardia (MAT) (6 patients , $12 \%$ ) being the least common finding . (Table 1)

\begin{tabular}{|c|c|c|c|c|}
\hline Characteristics & $\begin{array}{l}\text { Male } \\
(\mathrm{n}=18)\end{array}$ & $\begin{array}{l}\text { Female } \\
(\mathrm{n}=32)\end{array}$ & $\begin{array}{l}\text { Overall } \\
(\mathrm{n}=50)\end{array}$ & $\begin{array}{l}\mathrm{p} \\
\text { value }\end{array}$ \\
\hline $\begin{array}{l}\text { ECG } \\
\text { abnormalities }\end{array}$ & $\begin{array}{c}16 \\
(88.9 \%)\end{array}$ & $\begin{array}{c}31 \\
(96.9 \%)\end{array}$ & $\begin{array}{c}47 \\
(94 \%)\end{array}$ & $>0.05$ \\
\hline $\mathrm{P}^{\prime}$ pulmonale & $\begin{array}{c}16 \\
(88.9 \%)\end{array}$ & $\begin{array}{c}29 \\
(90.6 \%)\end{array}$ & $\begin{array}{c}45 \\
(90 \%)\end{array}$ & $>0.05$ \\
\hline \multicolumn{5}{|l|}{$\mathrm{R} / \mathrm{S}$ ratio } \\
\hline$>1$ & $\begin{array}{c}12 \\
(62.7 \%)\end{array}$ & $\begin{array}{c}20(37.5 \\
\%)\end{array}$ & $\begin{array}{c}32 \\
(62 \%)\end{array}$ & $>0.05$ \\
\hline$<1$ & $\begin{array}{c}6 \\
(33.3 \%)\end{array}$ & $\begin{array}{c}12 \\
(37.5 \%)\end{array}$ & $\begin{array}{c}18 \\
(36 \%)\end{array}$ & $>0.05$ \\
\hline RBBB & $\begin{array}{c}7 \\
(38.9 \%)\end{array}$ & $\begin{array}{c}12 \\
(37.5 \%)\end{array}$ & $\begin{array}{c}19 \\
(38 \%)\end{array}$ & $>0.05$ \\
\hline AF/MAT & $\begin{array}{c}1 \\
(5.6 \%)\end{array}$ & $\begin{array}{c}5 \\
(15.6 \%)\end{array}$ & $\begin{array}{c}6 \\
(12 \%)\end{array}$ & $>0.05$ \\
\hline
\end{tabular}

Echocardiography done in the studied patients showed evidence of varying degrees of pulmonary hypertension along with enlargement of right sided chambers of the heart . Tricuspid regurgitation peak gradient a useful marker for indirect evidence of pulmonary hypertension was studied in all the patients. Pulmonary hypertension defined as SPAP (Peak systolic pulmonary pressure ) value $>30 \mathrm{mmHg}$ was observed in all of the patients in the study group. The mean TRPG value studied was $63.76 \pm 20.57 \mathrm{mmHg}$ with the range of $26-100 \mathrm{mmHg}$ and their corresponding peak systolic pulmonary artery pressure (PASP) mean value was $75.26 \pm 21.18 \mathrm{mmHg}$. Among patients with evidence of pulmonary hypertension, 30 patients $(60 \%)$ had severe PAH , 14 patients (28\%) had moderate $\mathrm{PH}$ and 6 patients $(12 \%)$ had mild degree of pulmonary hypertension as shown in Table 2. Other parameters of right heart enlargement and function such as RA area, RV base and mid diameter, TAPSE, RIMP, S' were studied. The mean RV diameters were increased as compared to normal adult values and parameters for $\mathrm{RV}$ function like TAPSE and RIMP also showed that majority of patients had significant RV dysfunction in our study. (Table 3)

\begin{tabular}{lll}
\hline Table 2: Pulmonary hypertension Grade & \\
\hline Pulmonary hypertension & Numbers & Percentage \\
\hline Mild $(>30-50 \mathrm{mmHg})$ & 6 & $12 \%$ \\
\hline Moderate $(>50-70)$ & 14 & $28 \%$ \\
Severe $(>70 \mathrm{mmHg})$ & 30 & $60 \%$
\end{tabular}

Table 3. Echocardiographic RV parameters

\begin{tabular}{lll} 
& Range & Mean \\
\hline RA Area $(\mathrm{cm} 2)$ & $8.8-39$ & $20.57 \pm 6.8$ \\
\hline RV diameter (base )/cm & $3.6-6.8$ & $5.04 \pm 0.66$ \\
\hline RV diameter (mid)/cm & $3.4-6.8$ & $4.68 \pm 0.58$ \\
\hline RV wall thickness /cm & $0.5-1.1$ & $0.77 \pm 0.11$ \\
\hline TAPSE /cm & $0.9-2.3$ & $1.59 \pm 0.38$ \\
\hline TDI s' /cm/s & $6.7-19$ & $11.5 \pm 2.95$ \\
RV MPI & $0.35-0.98$ & $0.58 \pm 0.16$ \\
TRPG /mmHg & $26-110$ & $63.76 \pm 20.57$ \\
PASP & $36-120$ & $75.26 \pm 21.18$
\end{tabular}

Inferior venacava diameter (IVCd) at diastole is a surrogate marker for increased right atrial pressure and is useful for estimation of peak pulmonary artery pressure. The mean IVC diameter was $1.88 \pm 0.35 \mathrm{~cm}$ as shown in (Table 4).

Table 4. EchocardiogrpahicLV parameters and IVC size

\begin{tabular}{lll} 
& Range & Mean \\
\hline $\mathrm{LVDD} / \mathrm{cm}$ & $2.8-5.7$ & $4.01 \pm 0.64$ \\
\hline $\mathrm{LVSD} / \mathrm{cm}$ & $1.5-4.5$ & $2.48 \pm 0.63$ \\
$\mathrm{IVS} / \mathrm{cm}$ & $0.6-1.1$ & $0.79 \pm 0.09$ \\
$\mathrm{PW} / \mathrm{cm}$ & $0.6-1.2$ & $0.82 \pm 0.01$ \\
$\mathrm{EF} \%$ & $50-65$ & $60.34 \pm 3.89$ \\
\hline $\mathrm{IVC} \mathrm{d} / \mathrm{cm}$ & $1-2.4$ & $1.88 \pm 0.35$ \\
\hline${ }^{*} \mathrm{LVID}-\mathrm{LV}$ internal diastole diameter, & $\mathrm{LVSD}-\mathrm{LV}$ systole \\
diameter, IVS - Interventricular septum, PW- Posterior wall \\
thickness, EF - Ejection fraction.
\end{tabular}

\section{Discussion:}

COPD is associated with significant extra-pulmonary effects among which cardiac complications are most common. The cardiac manifestations of COPD are numerous. Impairment of $\mathrm{RV}$ function and alteration of pulmonary blood vessels are well 
known to complicate the clinical course of COPD and correlate inversely with survival. Long term changes with chronic pulmonary vascular remodeling and vasoconstriction impose increase in RV afterload and ultimately result in RV dilation and later dysfunction manifesting as corpulmonale. Although the true prevalence of $\mathrm{PH}$ in COPD is unknown, an elevation of pulmonary arterial pressure is reported to occur in $20 \%-90 \%$ of patients when measured by right heart catheterization. ${ }^{6}$ The level of PH has a prognostic value in COPD patients that has been demonstrated by several studies. In one of these studies, the 5 -year survival rates were $50 \%$ in patients with mild $\mathrm{PH}$ $(20-30 \mathrm{mmHg}), 30 \%$ in those with moderate to severe $\mathrm{PH}$ $(30-50 \mathrm{mmHg}$ ), and $0 \%$ in the small group of patients with very severe $\mathrm{PH}(>50 \mathrm{mmHg})$. Thus, a high degree of $\mathrm{PH}$ bears a poor prognosis in patients with COPD and this also has been observed in COPD patients receiving long-term oxygen therapy .? In our study , all 50 patients had evidence of pulmonary hypertension ( $\mathrm{SPAP}>30 \mathrm{mmHg}$ ) with majority of them ( 60 $\%$ ) having higher grades of pulmonary hypertension maybe because of the chronicity of the disease and the study was mainly done in admitted patients with COPD . There were significant evidence of right ventricular enlargement as well as decline in $\mathrm{RV}$ systolic function through various parameters studied by echocardiography. All COPD patients studied had shown an increase in RV enlargement in form of increased RV diameters $(\mathrm{RV}$ base $=5.04 \pm 0.66$ and $\mathrm{RV}$ mid $=4.68 \pm 0.58 \mathrm{~cm})$. RV systolic function as assessed by TAPSE and RIMP also showed values below normal adult population values which indicate majority of COPD patients studied had evidence of RV dysfunction as well. (TAPSE , mean $=1.59 \pm 0.38$, RIMP $=0.58 \pm 0.16)$. Saxena $\mathrm{N}$ et $\mathrm{al} .{ }^{8}$ showed tricuspid annular systolic velocity (TAPSE) is a useful measurement in determining right ventricular systolic function regardless of pulmonary artery pressures in a study of 52 patients. Evidence of right ventricular hypertrophy was also seen in most patients with the average $R V$ wall thickness of $0.77 \pm 0.11 \mathrm{~mm}$ as compared to normal adult value of 3-5 $\mathrm{mm}$.

These results indicate that further large scale studies using a more accurate assessment method for $\mathrm{PH}$ are warranted, to achieve a more detailed assessment of the RV dysfunction associated with COPD . Echocardiographic evaluation of right heart can be used as an important risk assessment tool for assessing RV function and pulmonary artery pressure and should constitute part of a periodic screening tool for all COPD patients. Regular cardiac monitoring by echo in these COPD patients can help to identify individuals at risk of increased morbidity and mortality, warranting close monitoring and aggressive treatment to prevent or delay complications.

Major limitation of the study was that it was a single centre study and with a small sample size as well as the patients studied were only those who were admitted in the hospital with acute exacerbations. The exact correlation to the severity of pulmonary hypertension with pulmonary function test of patients with each COPD patients also could not be done. So, a lot of COPD patients with mild to moderate form were not included which made a bias that higher group demonstrated severe form of pulmonary hypertension.

\section{Conclusion:}

This study reveals that chronic obstructive pulmonary disease with pulmonary hypertension is highly prevalent in Nepalese population. Echocardiographic right heart profile assessment should be an additional tool to detect and prognosticate patients with various degrees of pulmonary hypertension.

\section{Reference :}

1. Murray CJ, Lopez AD. Evidence based health policy-lessons from the Global Burden of disease Study. Science. 1996; 274:740-3. https://doi.org/10.1126/science.274.5288.740

2. Kasibowska-Kuzniar K, Jankowska R, Kuzniar T. Chronic obstructive pulmonary disease exacerbation - effects on quality of life. Pol Arch Med Wewn. 2005; 114: 1010-1015.

3. Gupta, N. K., et al. "Echocardiographic evaluation of heart in chronic obstructive pulmonary disease patient and its corelation with the severity of disease." Lung India: official organ of Indian Chest Society 28.2 (2011): 105.

4. Daniels LB,Krummen DE, Blanchard DG.Echocardiography inpulmonary vascular disease.CardiolClin 2004;22:383-99. https://doi.org/10.1016/j.ccl.2004.04.007

5. Brennan JM, Blair JE, Goonewardena S, Ronan A, Shah D, VasaiwalaS,et al. Reappraisal of the use of inferior vena cava for estimating right atrial pressure. J Am SocEchocardiogr 2007;20:857-61. https://doi.org/10.1016/j.echo.2007.01.005

6. Weitzenblum E, Hirth C, Ducolone A, Mirhom R, Rasaholinjanahary J, Ehrhart M. Prognostic value of pulmonary artery pressure In chronic COPD. Thorax. 1981; 36:752-8.https://doi.org/10.1136/thx.36.10.752

7. Oswald-Mammosser M, Weitzenblum E, Quoix E, Moser G, Chaouat A, Charpentier C, et al. Prognostic factors in COPD patients receiving long-term oxygen therapy. Chest 1995;107:1193-8.https://doi.org/10.1378/chest.107.5.1193

8. Saxena $\mathrm{N}$ et al Tricuspid annular systolic velocity: a useful measurement in determining right ventricular systolic function regardless of pulmonary artery pressures. Echocardiography. 2006 Oct; 23(9): 750-5. https://doi. org/10.1111/j.1540-8175.2006.00305.x
Cite this article as: Anish Hirachan, Arun Maskey, Ram Kishore Shah, et.al. Echocardiographic right heart study in patients with chronic obstructive pulmonary disease. Nepalese Heart Journal 2017;12(2): 9-11. http://dx.doi.org/10.3126/njh.v14i2.18496 
